\title{
Effect of Resin Coating on Adhesion of Composite Crown Restoration
}

\author{
Md. Rafiqul ISLAM ${ }^{1}$, Tsunehiko TAKADA ${ }^{1}$, Dinesh S. WEERASINGHE ${ }^{1}$, Md. Akhtar UZZAMAN ${ }^{1}$, \\ Richard M. FOXTON ${ }^{3}$, Toru NIKAIDO ${ }^{1}$ and Junji TAGAMI ${ }^{1,2}$ \\ ${ }^{1}$ Cariology and Operative Dentistry, Graduate School, Tokyo Medical and Dental University, 5-45, Yushima 1-Chome, \\ Bunkyo-ku, Tokyo, Japan \\ ${ }^{2}$ COE Program, FRMDRTB at TMDU, Graduate School, Tokyo Medical and Dental University, 5-45, Yushima 1-Chome, \\ Bunkyo-ku, Tokyo, Japan \\ ${ }^{3}$ Clinical Lecturer, Department of Conservative Dentistry, Guy's King's and St. Thomas' Dental Institute, London SE1 9RT, \\ UK \\ Corresponding author, Md. Rafiqul Islam E-mail:drrafiqulislam@gmail.com
}

Received November 17, 2005/Accepted February 10, 2006

\begin{abstract}
The purpose of this study was to evaluate the effect of a resin coating technique on the microtensile bond strength ( $\mu$ TBS) of resin cement to dentin in composite crown restorations. Crown preparations were done on human molars. A resin coating material, Hybrid Bond, was immediately applied to the prepared dentin and light-cured, while the tooth without resin coating acted as the control. An impression of the resin-coated tooth was taken, and a composite crown fabricated on the working cast. The composite crown was then bonded with a resin cement, Chemiace II. $\mu$ TBSs were measured at a crosshead speed of $1 \mathrm{~mm} / \mathrm{min}$, and the resin-coated group yielded significantly higher $\mu$ TBSs than the non-coated group $(\mathrm{p}<0.05)$. In terms of $\mu$ TBS values between the axial and occlusal surfaces, no regional differences in resin-dentin bond strength were detected $(\mathrm{p}<0.05)$. It was concluded that resin coating with Hybrid Bond significantly improved the $\mu$ TBS of resin cement to dentin in composite crown restorations.
\end{abstract}

Key words: Resin coating, Indirect restoration, Resin cement

\section{INTRODUCTION}

Resin cements have been widely advocated for luting indirect tooth-colored restorations. However, current resin cements do not always provide good bonding to dentin compared with the dentin bonding systems for direct composite restorations ${ }^{1,2)}$. In the early $90 \mathrm{~s}$, a resin coating technique was introduced for indirect restorations to minimize pulpal irritation and postoperative sensitivity ${ }^{3)}$. This technique also enables better bonding, sealing, and adaptation to dentin ${ }^{4,5)}$. These benefits then help to prevent contamination of the prepared dentin surfaces with temporary filling materials, blood, and saliva - which are clinical factors that could reduce the dentin bonding capacity of resin cements $^{6)}$.

Resin coating in combination with a dentin adhesive system and a low-viscosity microfilled resin has been recommended for the prepared cavity immediately after tooth preparation, just before taking the impression. This technique produces a hybrid layer and a tight sealing film on the dentin surface ${ }^{7-10)}$. However, the combination of a dentin bonding system and a low-viscosity microfilled resin creates a layer of more than $100 \mu \mathrm{m}$ thickness on the dentin surface $^{8)}$, which is too thick ${ }^{8)}$ for coating of crown preparations.

Recently, a thin-film coating material has been developed through the technology of single-step bonding systems ${ }^{11)}$. It was reported that the thin-film coating material could prevent marginal leakage beneath full cast crowns ${ }^{12)}$. However, there is little information on the dentin bonding performance of resin coating materials on teeth prepared for crowns.

Therefore, the purpose of this study was to evaluate the microtensile bond strength of resin cement to resin-coated dentin using a single-step coating material on teeth prepared for indirect composite crowns. In addition, the ultrastructure of the interface between the resin cement and dentin was examined by a scanning electron microscope (SEM). The null hypothesis of this study was that the resin coating material did not influence the bonding performance of composite crown restorations.

\section{MATERIALS AND METHODS}

\section{Specimen preparation}

Preparation methods of both resin-coated and noncoated samples for microtensile bond strength ( $\mu$ TBS) testing is illustrated in Fig. 1. Twenty-eight extracted, non-carious, human lower first molars, stored in normal saline at $4{ }^{\circ} \mathrm{C}$, were used in this study. Each tooth was prepared for a full veneer crown with slightly rounded internal line angles using a superfine diamond bur (SF 145, Shofu Co., Kyoto, Japan) mounted on a high-speed handpiece under water coolant. Dentin margin of the crown preparations was situated below the cementoenamel junction. Prepared tooth surfaces were also exam- 
ined with a stereoscope microscope (Nikon SMZ10, Tokyo, Japan) to ensure that they were free of retained enamel. The prepared teeth were then randomly divided into two groups: the experimental group (Group I) which received "resin coating", and the control group (Group II) "without resin coating".
Following which, each group was further divided into two sub-groups by the region: (i) occlusal and (ii) axial surfaces.

The materials used in this study, their compositions, batch numbers, and manufacturer names are presented in Table 1. In Group I, a resin coating

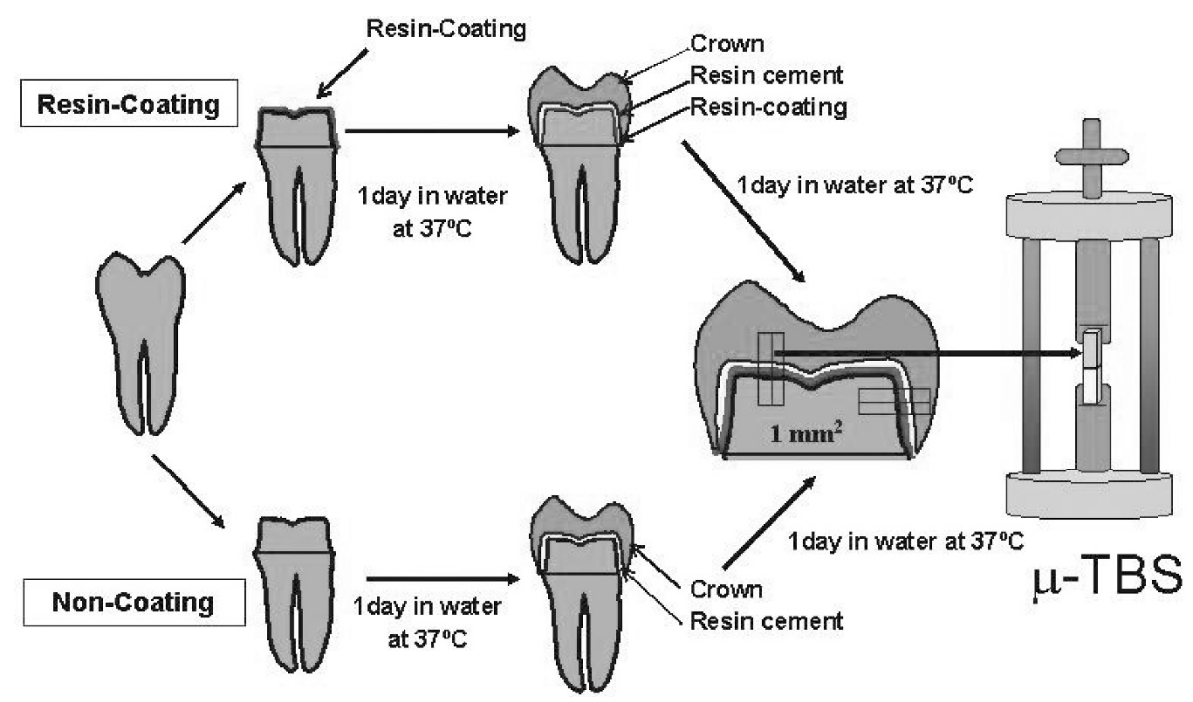

Fig. 1 Sample procedures for the microtensile bond strength test.

Table 1 Materials, manufacturers, batch numbers, and components

\begin{tabular}{|c|c|c|c|}
\hline Material & Manufacturer & Batch No. & Components \\
\hline $\begin{array}{l}\text { Resin coating material } \\
\text { Hybrid Bond }\end{array}$ & $\begin{array}{c}\text { Sun Medical Co., Moriyama, } \\
\text { Japan }\end{array}$ & 21210 & $\begin{array}{l}\text { Sponge: } p \text {-toluenesulfinate } \\
\text { salt and amine }\end{array}$ \\
\hline Resin cement & & 30527 & $\begin{array}{l}\text { Liquid: water, acetone, } \\
\text { 4-META, polyfunctional } \\
\text { acrylate, monomethacrylate, } \\
\text { photoinitiators, and } \\
\text { stabilizers }\end{array}$ \\
\hline Chemiace II & $\begin{array}{c}\text { Sun Medical Co., Moriyama, } \\
\text { Japan }\end{array}$ & GK1 & $\begin{array}{l}\text { Powder: zirconium, silica, } \\
\text { methacrylic ester polymer, } \\
\text { aromatic amine }\end{array}$ \\
\hline Silane primer & & GG1 & $\begin{array}{l}\text { Liquid: methacrylic ester, } \\
\text { acrylic ester, 4-META, } \\
\text { HEMA, BPO }\end{array}$ \\
\hline Porcelain Liner M & $\begin{array}{l}\text { Sun Medical Co., Moriyama, } \\
\text { Japan }\end{array}$ & $\begin{array}{l}\text { Liquid A } \\
31001\end{array}$ & $5 \%$ 4-META in MMA \\
\hline Indirect resin composite & & $\begin{array}{l}\text { Liquid B } \\
31001\end{array}$ & 4\% TMSPMA in MMA \\
\hline Estenia & $\begin{array}{c}\text { Kuraray Medical Co., Tokyo, } \\
\text { Japan }\end{array}$ & 0215CA & $\begin{array}{l}\text { Urethane monomer, } \\
\text { microfiller } 16 \text { wt } \% \text {, glass } \\
\text { filler } 76 \mathrm{wt} \%\end{array}$ \\
\hline
\end{tabular}

HEMA: 2-hydroxyethyl methacrylate; 4-META: 4-methacryloxyethyl trimellitate anhydride; MMA: methyl methacrylate; TMSPMA: 3-trimethoxysilylpropyl methacrylate; BPO: benzoyl peroxide 
material, Hybrid Bond (Sun Medical Co., Moriyama, Japan), was applied to the prepared dentin surface for 20 seconds and light-cured for 10 seconds with a halogen light curing unit (Optilux, Demetron Kerr, Danbury, CT, USA). In Group II, the prepared dentin was not given any treatment. A reversible (Aromaloid, GC Co., Tokyo, Japan) and irreversible hydrocolloid (Aroma fine DF II, GC Co., Tokyo, Japan) combination impression ${ }^{13)}$ was made of each tooth. The impressions were then cast in a Type III stone (Zo Gypsum, GC Co., Tokyo, Japan), and the composite crowns fabricated with an indirect resin composite (Estenia, Kuraray Medical Co., Tokyo, Japan) according to the manufacturer's instructions. Tooth specimens were stored in $37^{\circ} \mathrm{C}$ water without temporization for one day until the composite crowns were fabricated in the laboratory.

Fitting surface of the composite crowns was sandblasted with $50 \mu \mathrm{m}$ alumina (Jet Blast III, J Morita Corporation, Japan) for 10 seconds at an air pressure of $3.0 \mathrm{kgf} / \mathrm{cm}^{2}$ and cleaned ultrasonically in distilled water for 10 minutes. Trial insertion prior to cementation was performed to ensure a good fit for each crown. For cementation, both the resincoated and non-coated teeth were etched with $10 \%$ citric acid and 3\% ferric chloride (Green Activator, Sun Medical Co., Moriyama, Japan) for 10 seconds, rinsed, and gently air-dried. A silane-coupling agent, Porcelain Liner M (Sun Medical Co., Moriyama, Japan), was mixed and applied for 20 seconds to the fitting surface of the composite crown and dried. After that, one scoop of powder and three drops of liquid of dual-cured resin cement (Chemiace II, Sun Medical Co., Moriyama, Japan) were mixed together. The composite crown was then cemented to the prepared tooth. After 10 minutes, a direct composite (Clearfil AP-X, Kuraray Medical Co., Tokyo, Japan) was built up incrementally to create a flat crown with a height of $3-4 \mathrm{~mm}$ for microtensile bond testing. The teeth were stored in $37^{\circ} \mathrm{C}$ water for 24 hours, and then the margins were finished with a superfine diamond bur (V16ff, GC Co., Tokyo, Japan).

\section{Microtensile bond strength testing}

After removal of the specimens from water storage, each specimen was sectioned vertically using a slow rotating diamond saw (Isomet, Buehler Co., Lake Bluff, IL, USA) in a mesiodistal direction to obtain three to four slabs, each of $1 \mathrm{~mm}$ thickness approximately. Each slice was further sectioned vertically in a buccolingual direction to obtain composite-dentin beams with an approximately $1 \times 1 \mathrm{~mm}^{2}$ bonding area according to the technique for the 'non-trimming' version of microtensile test ${ }^{14)}$. Dimensions of each composite-dentin beam were checked with a digital caliper before the microtensile test.

Following this, each specimen was attached to a Bencore-Multi $\mathrm{T}$ testing apparatus (Danville engi- neering Co., San Ramen, CA, USA) with Zapit cyanoacrylate adhesive (Dental Ventures of America, Corona, CA, USA) and placed in a universal testing machine (EZ test, Shimadzu Co., Kyoto, Japan) for the $\mu$ TBS test at a cross-head speed of $1 \mathrm{~mm} / \mathrm{min}$. For each test group, 20 composite-dentin beams were obtained from the five bonded specimens. Data were analyzed using two-way ANOVA at 95\% level of confidence. The two factors analyzed were material and region.

\section{Scanning electron microscopic (SEM) analysis}

Subsequent to microtensile bond strength testing, the fracture mode of each specimen was first examined by visual inspection and then by a SEM. The specimens, having been fixed in $10 \%$ formalin, were desiccated and gold-coated for SEM observation (JSM5310LV, JEOL, Tokyo, Japan).

Fracture mode was classified into one of the six categories as follows: (A) Complete adhesive failure at dentin-resin cement; (B) Partial adhesive failure, where remnants of resin cement remained on dentin surface; (C) Cohesive failure within resin cement; (D) Complete adhesive failure at Hybrid Bond-resin cement interface; (E) Adhesive failure between $\mathrm{Hy}$ brid Bond and dentin; (F) Partial adhesive failure, where remnants of resin cement remained on coated dentin surface.

Fractional area of each failure mode in the debonded specimen was determined from the SEM micrographs using an image analyzer. The exact bonding area of each specimen was derived from the image analysis of digitized micrographs using an image analysis software (SemAfore X I 6, Program version 5.0; a digital image recording and processing system for SEM, JEOL, Insinööritoimisto J. Rimppi Oy, Finland). The area occupied by each failure mode on the fractured surface (Region of Interest; ROI) of one beam was first determined and expressed as a percentage of the total bonding surface area of that particular beam. Then, the area of each of the six failure modes was converted into a percentage of the respective test group, with 20 beams in each group.

The interface between the indirect composite and dentin with/without resin coating was also observed with a SEM. Specimens were prepared in the same manner as for the microtensile bond strength test and stored in water at $37^{\circ} \mathrm{C}$ for one day. Bonded specimens were then sectioned into two halves using a low-speed diamond saw microtome (Isomet, Buehler Co.) and embedded in self-curing epoxy resin (Epon 815, Nissin EM, Tokyo, Japan). After curing of the epoxy resin, the specimens were ground with silicon carbide papers under running water and then polished with diamond pastes down to a $0.25 \mu \mathrm{m}$ particle size (DP-Paste, P, Struers A/S, Ballerup, Denmark). Specimens were cleaned ultrasonically after each step. 
Polished specimens were then subjected to argon ion beam etching (EIS-1E, Elionix, Tokyo, Japan) for five minutes to disclose the interfacial structure, followed by sputter coating with gold ${ }^{15)}$.

\section{RESULTS}

Microtensile bond strength ( $\mu$ TBS)

The $\mu$ TBSs of resin cement to dentin with/without resin coating are shown in Table 2. Two-way ANOVA revealed that bond strength was influenced by resin coating $(\mathrm{F}=249.301, \mathrm{p}<0.0001)$, but not by region $(\mathrm{F}=1.483, \mathrm{p}=0.227)$. No specimens debonded prior to the $\mu$ TBS test. On both the axial and occlusal surfaces with resin coating, the bond strength was approximately $16 \mathrm{MPa}$, while those without resin coating yielded a bond strength circa 8 $\mathrm{MPa}$. Therefore, there were significant differences in bond strength between resin-coated and non-coated surfaces $(p<0.05)$.

\section{Fracture mode}

The fracture modes after $\mu$ TBS testing are summarized in Table 3. SEM pictures of typical fracture modes of each group are shown in Fig. 2. For the non-coated group, failure was mainly complete adhesive failure at the dentin-resin cement interface (group $\mathrm{A}=80 \%$ ) and partial adhesive failure, where remnants of resin cement remained on the dentin surface (group $B=20 \%$ ). In the resin-coated group, the majority of failures were cohesive failure within the resin cement (group $\mathrm{C}=67.5 \%$ ) and complete ad- hesive failure at Hybrid Bond-resin cement interface (group $\mathrm{D}=17.5 \%$ ).

\section{Interface observation}

SEM images of the indirect resin composite-dentin interface of the bonded specimens are shown in Fig. 3. Good adaptation at the interface was exhibited in both the resin-coated (Figs. $3 \mathrm{a}$ and $3 \mathrm{~b}$ ) and noncoated groups (Figs. 3c and 3d). For the resin-coated specimens, thickness of the resin coating layer with Hybrid Bond was approximately $1 \mu \mathrm{m}$ at the occlusal surface (Fig. 3a) and $1-1.5 \mu \mathrm{m}$ on the axial surface (Fig. 3b). As for the thickness of the hybrid layer, it was less than $1 \mu \mathrm{m}$ in the resin-coated group. In the non-coated group, a thicker hybrid layer of approximately $2.5-3 \mu \mathrm{m}$ was observed at the interface between the resin cement and dentin on both the occlusal and axial surfaces (Figs. $3 \mathrm{c}$ and $3 \mathrm{~d}$ respectively).

\section{DISCUSSION}

Dual-cure type resin cements contain both chemical components and photoinitiators, which serve to accelerate the polymerization of the cement matrix ${ }^{16)}$. As a result, dual-cured resin cements achieve significantly higher bond strengths than chemically cured resin cements immediately after light curing ${ }^{1,17)}$. Chemiace II is categorized as a dual-cure resin cement. However, the main curing mode of Chemiace II is chemical polymerization, while photopolymerization is only an option. According to

Table $2 \mu$ TBSs of resin cement to dentin with/without resin coating

\begin{tabular}{ccc}
\hline \multirow{2}{*}{ Region } & \multicolumn{2}{c}{ Microtensile bond strength $(\mathrm{MPa})$} \\
\cline { 2 - 3 } & Coated & Non-Coated \\
\hline Occlusal surface & $16.3 \pm 5.8^{\mathrm{a}}$ & $8.1 \pm 2.3^{\mathrm{b}}$ \\
Axial surface & $15.6 \pm 5.4^{\mathrm{a}}$ & $7.6 \pm 4.8^{\mathrm{b}}$ \\
\hline
\end{tabular}

$\mathrm{n}=20$ for each group; Mean values (Mean \pm SD) with different superscripts are significantly different from each other $(\mathrm{p}<0.05)$

Table 3 Summary of fracture modes (\%)

\begin{tabular}{cccccccc}
\hline \multirow{2}{*}{ Group } & Region & \multicolumn{7}{c}{ Failure mode $(\%)$} \\
\cline { 2 - 8 } & & $\mathrm{A}$ & $\mathrm{B}$ & $\mathrm{C}$ & $\mathrm{D}$ & $\mathrm{E}$ & $\mathrm{F}$ \\
\hline \multirow{2}{*}{ Non-coated } & Occlusal & 78 & 22 & 0 & 0 & 0 & 0 \\
& Axial & 82 & 18 & 0 & 0 & 0 & 0 \\
\multirow{3}{*}{ Resin-coated } & Occlusal & 0 & 0 & 65 & 20 & 5 & 10 \\
& Axial & 0 & 0 & 70 & 15 & 5 & 10 \\
& & & &
\end{tabular}

A: Complete adhesive failure at dentin/resin cement interface; B: Partial adhesive failure, where remnants of resin cement remained on dentin surface; C: Cohesive failure within resin cement; D: Complete adhesive failure at Hybrid Bond/resin cement; E: Adhesive failure between Hybrid Bond and dentin; F: Partial adhesive failure, where remnants of resin cement remained on coated dentin surface. 

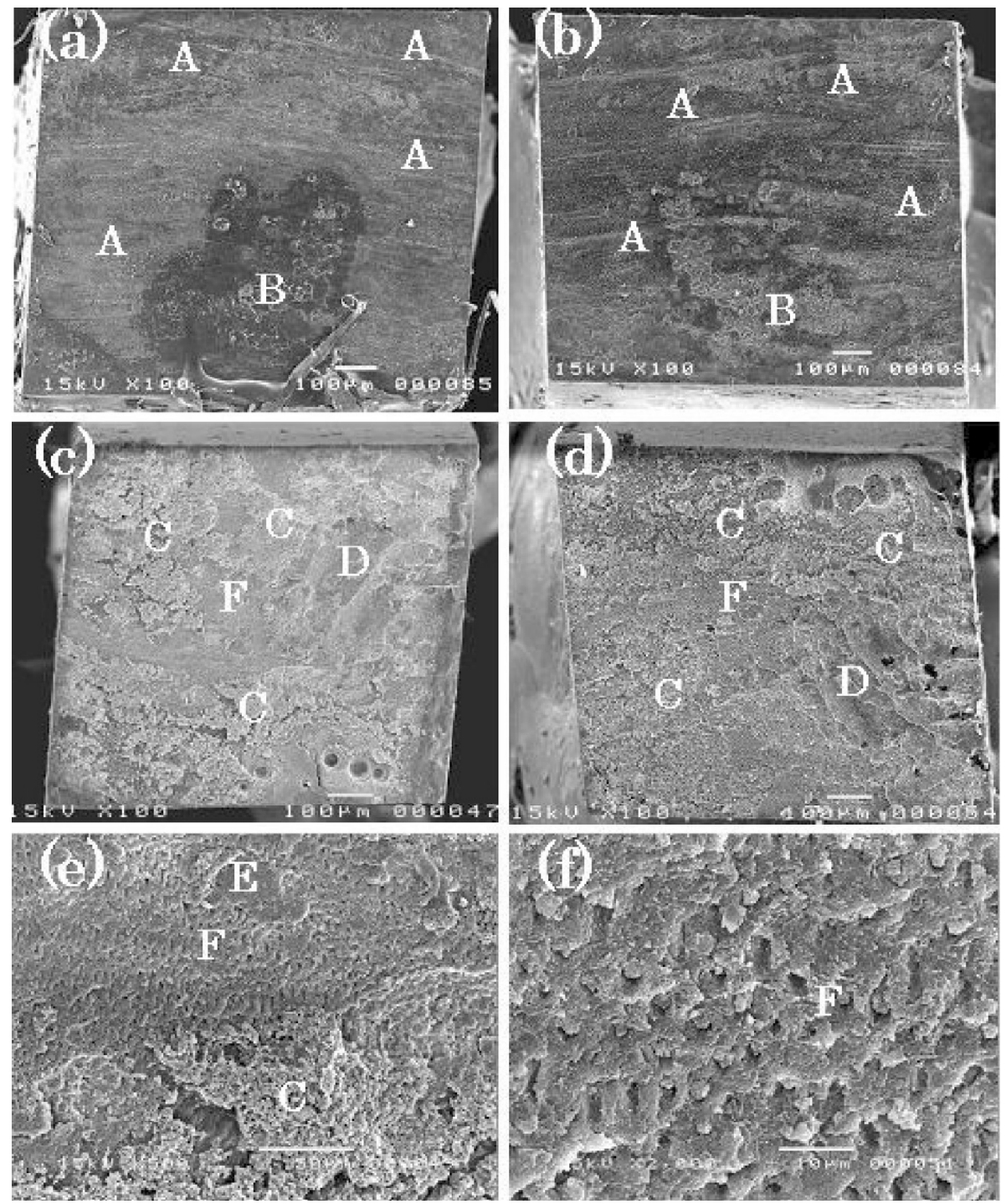

Fig. 2 SEM images of typical fracture modes of specimens after debonding:

(a) Non-coated specimen on crown side $(\times 100)$;

(b) Non-coated specimen on dentin side $(\times 100)$;

(c) Coated specimen on crown side $(\times 100)$;

(d) Coated specimen on dentin side $(\times 100)$;

(e) Coated specimen on dentin side $(\times 500)$;

(f) Coated specimen on dentin side of region $\mathrm{F}(\times 2000)$

Fracture modes are classified as: A - Complete adhesive failure at dentin-resin cement; B - Partial adhesive failure, where remnants of resin cement remained on dentin surface; C - Cohesive failure within resin cement; D - Complete adhesive failure at Hybrid Bond-resin cement interface; E - Adhesive failure between Hybrid Bond and dentin; F - Partial adhesive failure, where remnants of resin cement remained on coated dentin surface.

the manufacturer, Chemiace II contains an additional initiator which is activated by light; it is however not disclosed. Therefore, Chemiace II was chemically polymerized in this study. It should also be mentioned that Chemiace II contains an adhesion promoting monomer, 4-META (4-methacryloxyethyl trimellitate anhydride). It is believed that 4-META promotes penetration of monomers into demineralized tooth structure, thereby resulting in enhanced dentin bond strength by virtue of the formation of a hybrid layer ${ }^{18)}$.

The resin coating material, Hybrid Bond, is cate- 

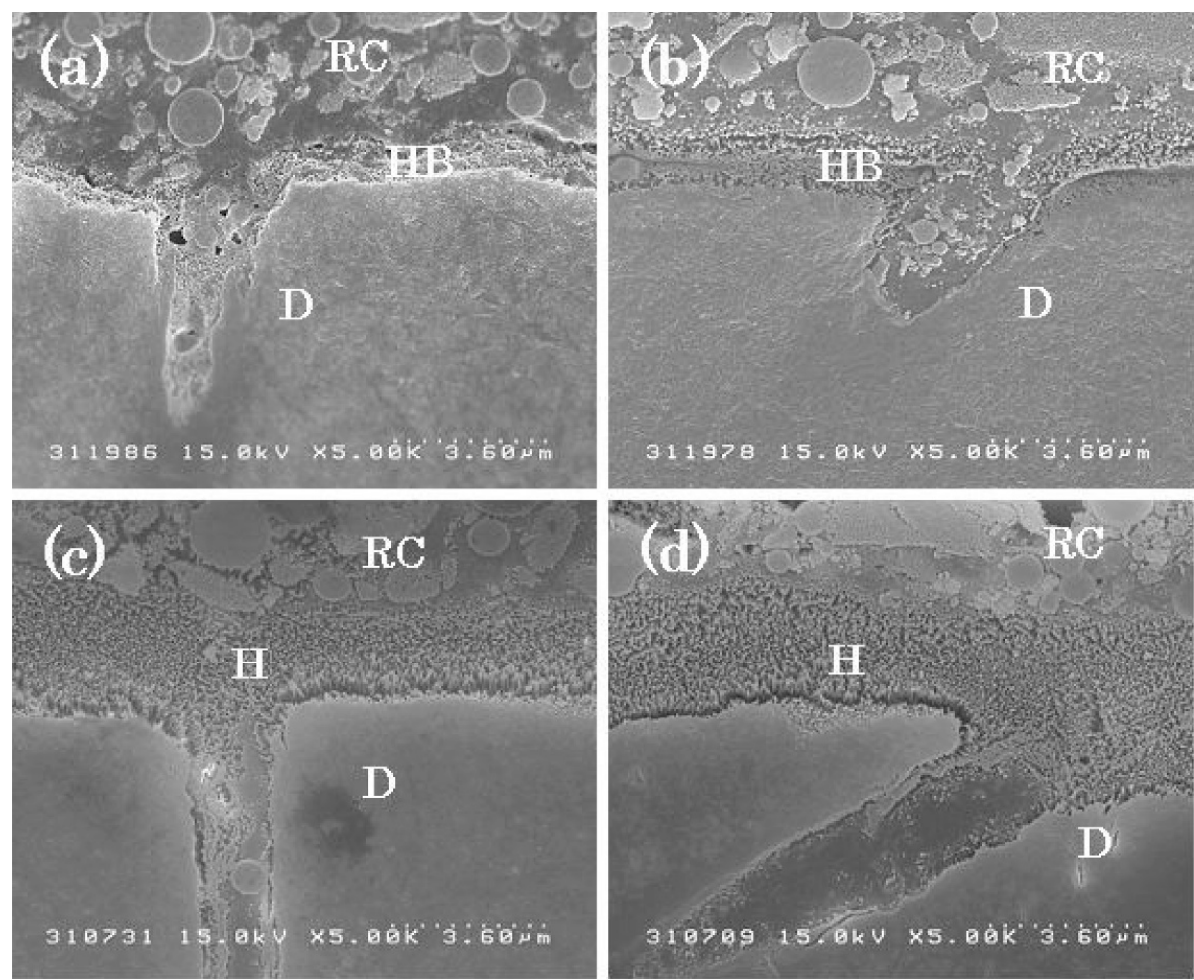

Fig. 3 SEM photomicrographs of the indirect resin composite-dentin interface on the occlusal and axial walls of the dentin of bonded specimens (RC: Resin cement; HB: Hybrid Bond; H: Hybrid layer; D: Dentin).

(a) Occlusal surface (coated with HB);

(b) Axial surface (coated with HB);

(c) Occlusal surface (non- coated);

(d) Axial surface (non- coated).

On the occlusal surface, Hybrid Bond coating thickness was approximately 1 $\mu \mathrm{m}$ (Fig. 3a); on the axial surface, coating thickness was approximately 1-1.5 $\mu \mathrm{m}$ (Fig. 3b). On the occlusal and axial surfaces of the non-coated group, hybrid layer thickness was approximately $2.5-3 \mu \mathrm{m}$ (Figs. 3c and $3 \mathrm{~d}$ ).

gorized as a single-step self-etching primer which is composed of an adhesive and a sponge. The sponge contains co-activators of $p$-toluene sulfinate salt and an aromatic amine that promote polymerization at the adhesive-tooth interface ${ }^{11)}$. It has been reported that Hybrid Bond applied to the flat dentin surface created a thin film, 5-6 $\mu \mathrm{m}$ thick, which is appropriate for resin coating a crown preparation ${ }^{11)}$.

In the present study, the resin-coated group demonstrated significantly higher $\mu$ TBSs than the noncoated group at both occlusal and axial sites. When the dentin surface was resin-coated, the fracture modes were predominantly cohesive failure within resin cement and complete adhesive failure at the $\mathrm{Hy}$ brid Bond-resin cement interface. This observation was supported by the relatively higher bond strength of the Hybrid Bond-dentin interface. The bonding mechanism between Hybrid Bond and resin cement is believed to be due to the formation of an interpenetrating polymer network (IPN) ${ }^{19)}$. Therefore, even if the restoration fractures, the resin coating material can still protect the prepared dentin from chemical, physical, and biological insults.

SEM observation revealed good adaptation at the interface in both the resin-coated and non-coated groups. The micromorphology of the interfaces showed good adaptation of the resin cement and adhesive system to the underlying dentin. For the resin-coated specimens, the film thickness of Hybrid Bond was approximately $1 \mu \mathrm{m}$ on the occlusal surface and $1-1.5 \mu \mathrm{m}$ on the axial surface. Therefore, the film thickness of Hybrid Bond was influenced by region. For the coated specimens, thickness of the hybrid layer was less than $1 \mu \mathrm{m}$ on the occlusal and axial walls due to optimal infiltration of Hybrid Bond. In the non-coated group, a thicker hybrid layer, approximately 2.5-3 $\mu \mathrm{m}$ thick, was observed at the interface between Chemiace II and dentin treated with the 10-3 solution because of the stronger acidity of 10-3 solution than that of Hybrid Bond ${ }^{11)}$. 
No regional differences in bond strength were found between the axial and occlusal surfaces in the present study. However, regional difference in dentin bond strength has been reported to depend on material properties, specimen preparation, heterogeneity of bonding substrate, and technique sensitivity ${ }^{20-25)}$.

Exposed dentinal tubules in intact dentin are more permeable than caries-affected dentin ${ }^{26)}$. The contents of dentinal tubules may change because of thermal influences or osmotic gradients that result in tooth sensitivity and pulpal inflammation due to the presence of bacteria on the prepared surface ${ }^{27,28)}$. Therefore, optimal sealing of prepared dentin is important to protect dentin and pulp tissue in vital teeth, since a conventional luting cement has poor dentin adhesion and lacks a peripheral biological seal $^{29)}$. Kosaka et $a l .{ }^{12)}$ reported that resin coating of crown preparations with Hybrid Bond prevented marginal leakage beneath full cast crowns. It was also reported that the barrier-like film layer minimized pulp irritation and postoperative sensitivity ${ }^{4,11)}$.

It was shown that increasing the bond strength of the luting material helped to increase the fracture strength of the restorative material ${ }^{2)}$. Furthermore, Kitasako et $a l^{30}{ }^{3}$ indicated that the resin coating technique enhanced the dentin bond durability of resin cement ${ }^{30)}$. In the light of these reports, resin coating with Hybrid Bond might have a positive impact on the durability of indirect restorations. Against this background, further in vitro and in vivo studies are required on the application of Hybrid Bond in indirect composite restorations.

\section{CONCLUSIONS}

Within the limitations of the present study, the following conclusions were drawn:

1. Resin coating with Hybrid Bond significantly improved the $\mu$ TBS of Chemiace II to dentin beneath composite crown restorations.

2 . There were no regional differences in $\mu$ TBS between the axial and occlusal surfaces of the prepared teeth.

\section{ACKNOWLEDGEMENTS}

This work was supported by a grant for the Center of Excellence Program for Frontier Research on Molecular Destruction and Reconstruction of Tooth and Bone at Tokyo Medical and Dental University. The authors wish to thank Mr. Masaomi Ikeda for his great assistance in statistical analysis.

\section{REFERENCES}

1) Burrow MF, Nikaido $T$, Satoh M, Tagami J. Early bonding of resin cements to dentin-effect of bonding environment. Oper Dent 1996; 21: 196-202.
2) Furakawa K, Inai N, Tagami J. The effects of luting resin bond to dentin on the strength of dentin supported by indirect resin composite. Dent Mater 2002; 18: $136-142$.

3) Tagami J, Kitasako Y, Sonoda H. Pulp protection and restoration with adhesive resin. Jpn Adhes Dent 1999; 17: $56-60$.

4) Nikaido T, Yoda A, Foxton RM, Tagami J. A resin coating technique to achieve minimal intervention in indirect resin composites: A clinical report. Int Chin J Dent 2003; 3: 62-68.

5) Peters MC, McLean ME. Minimally invasive operative care. Part I: Minimal intervention and concepts for minimally invasive cavity preparations. J Adhes Dent 2001; 3: 7-16.

6) Nakano M, Takada T, Nikaido T, Tagami J. Effect of impression material on adhesion of resin cement to resin coated teeth. Jpn Adhes Dent 1999; 17: 198-204.

7) Jayasooriya PR, Pereira PN, Nikaido T, Tagami J. Efficacy of a resin coating on bond strengths of resin cement to dentin. J Esthet Restor Dent 2003; 15: 105-113.

8) Jayasooriya PR, Pereira PN, Nikaido T, Burrow MF, Tagami J. The effect of a "resin coating" on the interfacial adaptation of composite inlays. Oper Dent 2003; 28: 28-35.

9) Nikaido T, Takada T, Burrow MF, Tagami J. The early bond strength of dual cured resin cement to enamel and dentin. J Jpn Dent Mater 1992; 11: 910-915.

10) Nikaido T, Koh Y, Satoh M. Effect of temporary filling materials on adhesion of dual cured resin cement to low viscosity resin. J Jpn Dent Mater1993; 12: 655661.

11) Nikaido T, Nakaoki $Y$, Ogata M, Foxton RM, Tagami J. The resin-coating technique: Effect of a single-step bonding system on dentin bond strengths. Jpn Adhes Dent 2003; 5: 293-300.

12) Kosaka S, Kajihara H, Kurashige H, Tanaka T. Effect of resin coating as a means of preventing marginal leakage beneath full cast crowns. Dent Mater J 2005; 24 (1): 117-122.

13) Takano Y, Nikaido T, Tagami J. Visual and SEM observations of resin coated dentin after taking impression. Jpn Adhes Dent 2000; 19 (2): 117-124.

14) Shono Y, Ogawa T, Terashita M, Carvalho RM, Pashley EL, Pashley DH. Regional measurement of resin-dentin bonding as an array. J Dent Res 1999; 78: 699-705.

15) Inokoshi $S$, Hosoda H, Harnirattisai C, Shimada Y. Interfacial structure between dentin and seven dentin bonding systems revealed using argon ion beam etching. Oper Dent 1993; 18: 8-16.

16) Kanno T, Ogata M, Foxton RM, Nakajima M, Tagami J, Miura H. Microtensile bond strength of dual-cure resin cement to root canal dentin with different curing strategies. Dent Mater J 2004; 23: 550-556.

17) Shimura R, Nikaido T, Yamauti M, Ikeda M, Tagami J. Influence of curing method and storage condition on microhardness of dual-cue resin cements. Dent Mater J 2005; 24 (1) : 70-75.

18) Nakabayashi N, Kojima K, Masuhara E. The promo- 
tion of adhesion by the infiltration of monomers in tooth substrates. J Biomed Mater Res 1982; 16: 265273.

19) Nikaido $T$, Nakajima $M$, Higashi $T$, Kanemura $N$, Pereira PNR, Tagami J. Shear bond strengths of a single-step bonding system to enamel and dentin. Dent Mater J 1997; 16(1): 40-47.

20) Prati C, Erickson R, Tao L, Simpson MD, Pashley DH. Measurement of dentin permeability and wetness using Periotron device. Dent Mater1992; 7: 268-273.

21) Tao L, Pashley DH. Shear bond strength to dentin: Effects of surface treatments, depth, and position. Dent Mater 1988; 4: 371-378.

22) Suzuki T, Finger WJ. Dentin adhesives: Site of dentin vs. bonding of composite resins. Dent Mater 1988; 4: 379-383.

23) Tao L, Tagami J, Pashley DH. Pulpal pressure and bond strengths of Superbond and Gluma. Am J Dent 1991; 4: 73-76.

24) Prati C, Pashley DH. Dentin wetness, permeability and thickness and bond strength of adhesive systems. Am
J Dent 1992; 5: 33-38.

25) Pereira PN, Okuda M, Sano H, Yoshikawa T, Burrow MF, Tagami J. Effect of intrinsic wetness and regional difference on dentin bond strength. Dent Mater 1999; 15: 46-53.

26) Mjör IA, Ferrari M. Pulp-dentin biology in restorative dentistry. Part 6: Reactions to restorative materials, tooth-restoration interfaces, and adhesive techniques. Quintessence Int 2002; 33: 35-63.

27) Brännström $M$, Astrom A. The hydrodynamics of the dentin: Its possible relationship to dentinal pain. Int Dent J 1972; 22: 219-227.

28) Bergenholtz G. Effect of bacterial products on inflammatory reactions in the dental pulp. Scand J Dent Res 1977; 85: 122-129.

29) Christensen GJ. Resin cement and post-operative sensitivity. J Am Dent Assoc 2000; 131: 1197-1199.

30) Kitasako Y, Burrow MF, Nikaido T, Tagami J. Effect of resin-coating technique on dentin tensile bond strengths over 3 years. J Esthet Restor Dent 2002; 14: 115-122. 